\title{
Theoretical Model for the Performance of Liquid Ring Pump Based on the Actual Operating Cycle
}

\author{
Si Huang, Jing He, Xueqian Wang, and Guangqi Qiu \\ School of Mechanical and Automotive Engineering, South China University of Technology, Guangzhou 510640, China \\ Correspondence should be addressed to Si Huang; huangsi@scut.edu.cn
}

Received 17 May 2017; Revised 9 July 2017; Accepted 27 July 2017; Published 28 August 2017

Academic Editor: Ryoichi Samuel Amano

Copyright (C) 2017 Si Huang et al. This is an open access article distributed under the Creative Commons Attribution License, which permits unrestricted use, distribution, and reproduction in any medium, provided the original work is properly cited.

\begin{abstract}
Liquid ring pump is widely applied in many industry fields due to the advantages of isothermal compression process, simple structure, and liquid-sealing. Based on the actual operating cycle of "suction-compression-discharge-expansion," a universal theoretical model for performance of liquid ring pump was established in this study, to solve the problem that the theoretical models deviated from the actual performance in operating cycle. With the major geometric parameters and operating conditions of a liquid ring pump, the performance parameters such as the actual capacity for suction and discharge, shaft power, and global efficiency can be conveniently predicted by the proposed theoretical model, without the limitation of empiric range, performance data, or the detailed 3D geometry of pumps. The proposed theoretical model was verified by experimental performances of liquid ring pumps and could provide a feasible tool for the application of liquid ring pump.
\end{abstract}

\section{Introduction}

Liquid ring pump is a kind of rotary displacement machines, including liquid ring vacuum pump and liquid ring compressor. Owing to the advantages of isothermal compression process, simple structure, and liquid-sealing, liquid ring pump is widely applied in petroleum, chemical, power, metallurgy, pharmaceutical, and light industry and other fields, particularly suitable for the pumping of flammable, explosive, toxic, and harmful gases like hydrogen, oxygen, nitrogen, chlorine, ethylene, acetylene, propane, natural gas, and carbon dioxide. However, there are still some problems such as a higher power consumption, lower suction vacuum degree, and unstable operation in application of liquid ring pump. The theoretical result considerably deviates from the actual performance due to the lack of the fundamental study on the performance and restricts the improvement of performance and reliability of liquid ring pump. Therefore, it is of significant scientific and application values to carry out the fundamental study on the operating theory and performance of the liquid ring pump.

The operating principle of the liquid ring pump is illustrated in Figure 1. With the revolution of the impeller, the operating liquid is ejected outwards due to centrifugal forces and forms a liquid ring. Owing to the eccentricity of the impeller to the casing, a crescent-shaped chamber forms between the impeller hub and the liquid ring. The impeller blades divide the crescent-shaped chamber into several cells of different volumes. As the impeller runs, the cells in the range of the suction port become larger and suck the gas through the suction port. In the part opposite to the suction port, the gas is compressed in the reducing cells and emitted through the discharge port. Each revolution of the impeller corresponds to one operating cycle. Consequently, liquid ring pumps are the rotating machines with reciprocating pump characteristics and the ring liquid takes on the function of a reciprocating piston.

Since the first liquid ring pump was invented, many scholars have carried out a variety of work on the design and industrial application of liquid ring pumps [1-6]. Compared with the work on the other types of pumps and compressors, however, there were few reports of the fundamental studies on liquid ring pumps. Referring to ideal operating cycle theory of "suction-compression-discharge" in reciprocating compressor, Pfleiderer [7] derived an equation for theoretical suction capacity in liquid ring pump and developed a theoretical model for the compression ratio and the liquid ring 
TABLE 1: Calculation models of gas volume flow and shaft power.

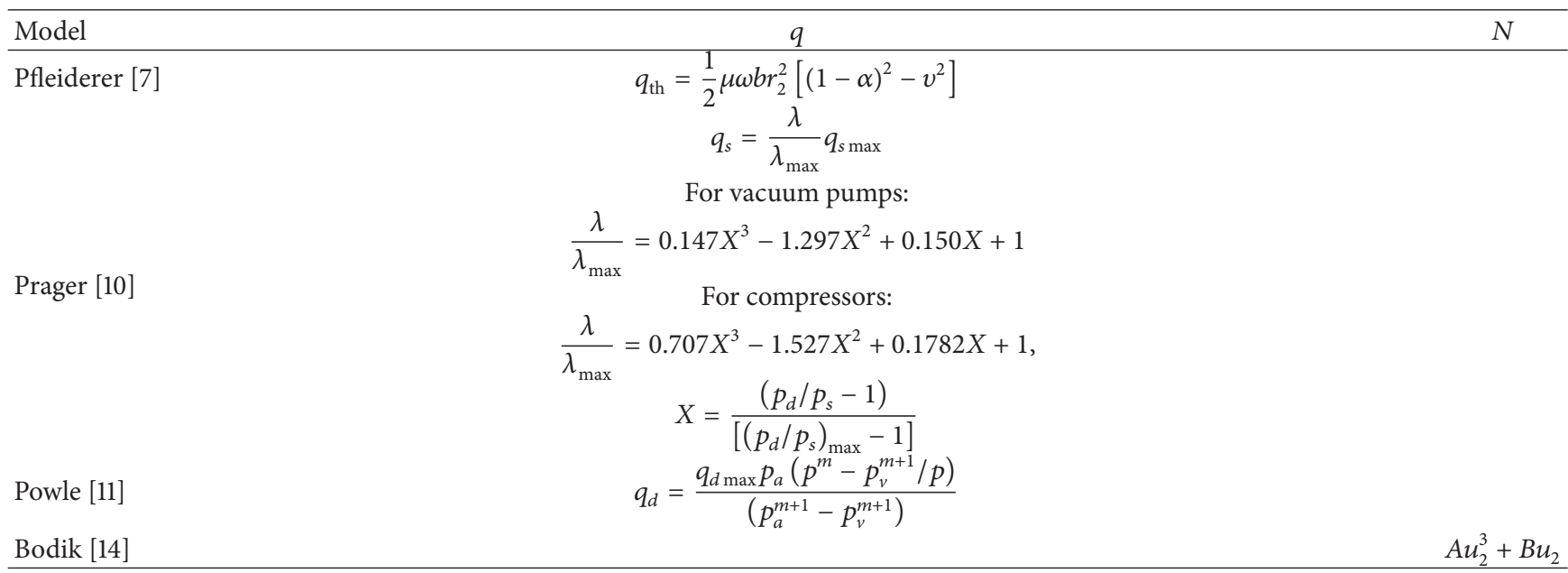

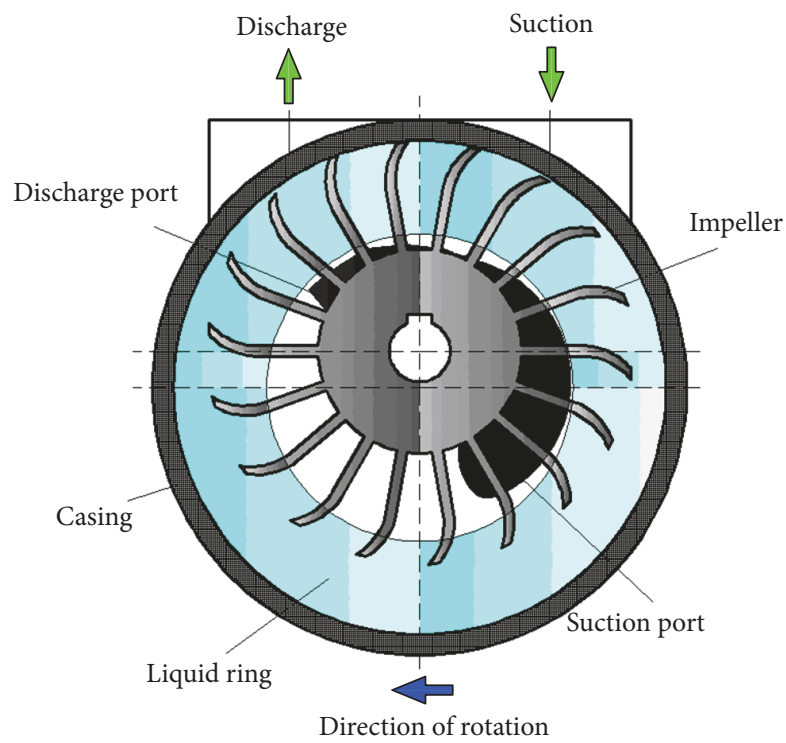

FIGURE 1: Operating principle of a liquid ring pump.

surface at each circumferential angle in the pump. Schulz [8] and Segebrecht [9], respectively, deduced similar equations for the theoretical suction capacity. So far, the theoretical model and the equations of theoretical suction capacity have been mainly used as reference for design of liquid ring pump. As shown in Table 1, the theoretical suction capacity, determined by the impeller rotational speed and the geometric parameters of liquid ring pump, remains constant regardless of the compression ratio of discharge pressure to suction pressure. This result obviously deviates from the actual situation, especially when the compression ratio is relatively high. To solve this problem, Prager [10] correlated an empirical formula for the ratio of the actual suction capacity to the maximum actual suction capacity, based on experimental performance data of liquid ring pump, but the validity of the statistical formula was restricted by the number of samples and the unknown maximum actual suction capacity. On the other hand, it was found from the actual applications that the minimum suction pressure of the liquid ring pump was close to the saturated vapor pressure of the operating liquid. Thus, Powle [11] developed an equation for the ratio of the actual discharge capacity to the maximum actual discharge capacity as a function of vapor pressure of the operating liquid and index of expansion process in the pump, but the maximum actual discharge capacity should be given in advance.

Concerning the power of liquid ring pump, due to the absorption and the removal of the heat by the operating liquid, the gas compression process in the liquid ring pump is generally regarded as isothermal one, so the formula for the isothermal compression power of the ideal gas is commonly used to calculate the effective power of the liquid ring pump [12, 13]. Bodik [14] deduced an approximate relation between the shaft power and rotational speed of liquid ring pump (Table 1). Besides the effective power, the shaft power includes the power consumed by volumetric losses, flow losses, and mechanical losses, but the coefficients in Bodik's power formula could not be determined. Recently, some investigators [15-18] used CFD numerical approach to simulate 3D flows and predicted performance of liquid ring pumps. Although numerical approach plays an important role for understanding internal flow field of liquid ring pump, it is still hard for practical application, due to the restriction of detailed 3D geometry of liquid ring pump, consumption of computation time, and the accuracy of gas-liquid twophase flow model. In this paper, therefore, a convenient and universal theoretical model is proposed for the performance prediction of liquid ring pump based on the actual operating cycle, to obtain the rules of operating cycle performance and of power consumption in liquid ring pumps, without limitation of statistical range or the detailed 3D geometry.

\section{Theoretical Model}

2.1. Actual Operating Cycle of Liquid Ring Pump. The traditional theory [7] of liquid ring pump was based on the ideal operating cycle of "suction-compression-discharge," 


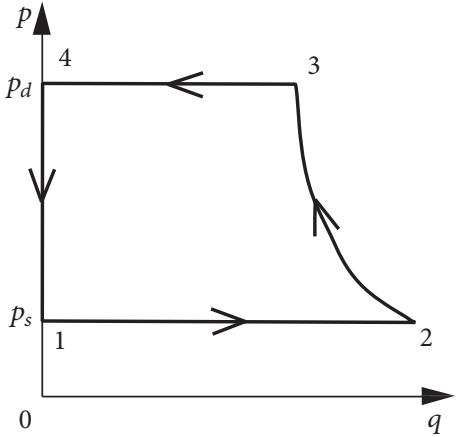

(a) Ideal

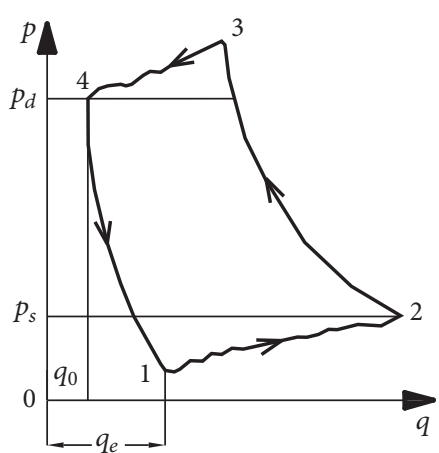

(b) Actual

FIGURE 2: Diagram $p-q$ of gas operating cycle in a liquid ring pump.

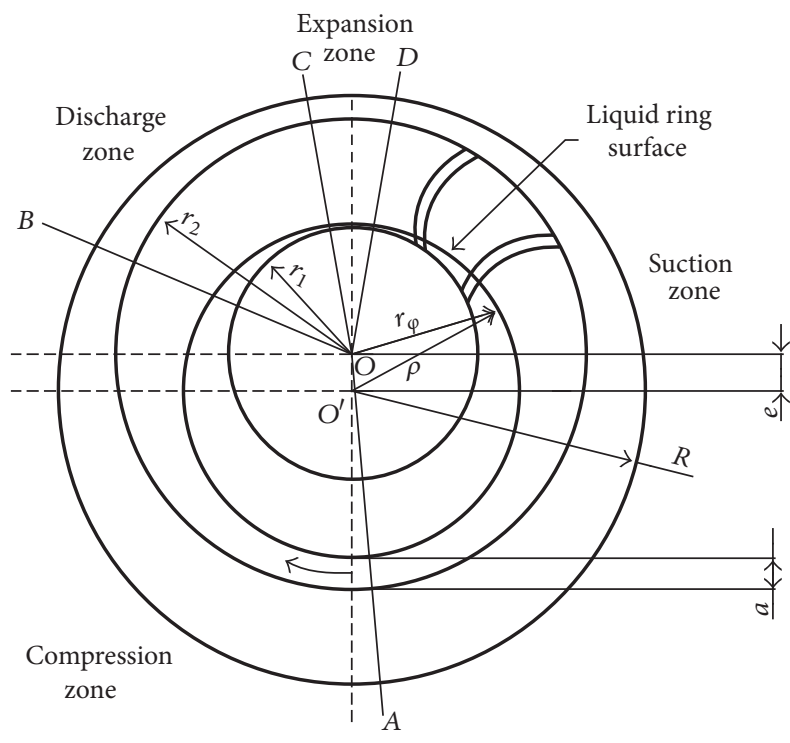

FIGURE 3: Geometric parameters in a liquid ring pump.

which was composed of three processes. During the suction process (Curves 1-2 shown in Figure 2(a)), the suction pressure $p_{s}$ keeps constant and reaches the maximum suction capacity $q_{\mathrm{th}}$. In the compression process (Curves 2-3), the gas volume reduces and the pressure increases to reach the discharge pressure $p_{d}$. In the discharge process (Curves $3-4)$, the discharge pressure $p_{d}$ keeps constant and all the gas is discharged from the pump. The corresponding zones in a liquid ring pump are divided into the suction zone (Sector $D O A$ ), the compression zone (Sector $A O B$ ), and the discharge zone (Sector BOC) as shown in Figure 3. Like the actual operating principle of reciprocating compressor, however, some residual gas (capacity is $q_{o}$ ) is still available in the liquid ring pump after gas discharge and returns to the suction zone; the residual gas changes to $q_{e}$ in capacity after a process of expansion (Curves 4-1 in Figure 2(b)) and goes to the next operating cycle. Thus, the actual operating cycle is composed of four processes: suction-compression-discharge-expansion, in which expansion process takes place at the expansion zone (Sector COD) shown in Figure 3. The actual suction capacity in a liquid ring pump is $q_{s}=q_{\mathrm{th}}-q_{e}$ (if $\left.p_{s} \leq p_{v}, q_{s}=0\right)$. The residual gas and its expansion process were not taken into account in the theoretical model for ideal operating cycle of liquid ring pump, resulting in deviation between theoretical and practical results.

Therefore, the theoretical model in the present work is to supplement an expansion process on the basis of the ideal operating cycle model. For the integrity of the model, the formulas in each zone are given in detail below.

(1) Suction Zone. The definition of geometric parameters in the liquid ring pump is shown in Figure 3. The distance from any point on the liquid ring surface in the suction zone to the center of the impeller is expressed as

$$
r_{\varphi}=r_{2} \sqrt{\frac{2(R-\rho)}{\mu r_{2}}+v^{2}},
$$

where

$$
\rho=r_{2} \sqrt{1+\left(\frac{e}{r_{2}}\right)^{2}+2 \frac{e}{r_{2}} \cos \varphi} .
$$

Theoretical suction capacity $q_{\text {th }}$ is defined as the gas volume flow through the OA section assuming that the liquid ring pump inhales fully:

$$
q_{\mathrm{th}}=\frac{1}{2} \mu \omega b r_{2}^{2}\left[(1-\alpha)^{2}-v^{2}\right] .
$$

(2) Compression Zone. The distance from any point on the liquid ring surface in the compression zone to the center of the impeller is

$$
r_{\varphi}=r_{2} \sqrt{\frac{(1-\alpha)^{2}+(\sigma-1) v^{2}}{\sigma}} .
$$

The compression ratio $\sigma$ of the pressure at the circumferential angle $\varphi$ to the suction pressure needs to solve an algebraic equation:

$$
\frac{1}{\sigma^{2}}=A^{2}\left(1-\frac{\sigma-1}{\varepsilon}\right)
$$

where $A=2(R-\rho) / \mu r_{2}\left[(1-\alpha)^{2}-v^{2}\right] ; \varepsilon=g \omega^{2} r_{2}^{2} / 2 p_{s}$. 
(3) Discharge Zone. The distance from any point on the liquid ring surface in the discharge zone to the center of the impeller is expressed as

$$
r_{\varphi}=r_{2} \sqrt{v^{2}+\frac{2(R-\rho)}{\mu r_{2}} \sqrt{\frac{1}{3}\left(1+\frac{1}{\varepsilon}\right)}} .
$$

(4) Expansion Zone. The distance from any point on the liquid ring surface in the expansion zone to the center of the impeller is also calculated by (6). Therefore, the full shape of liquid ring surface in the liquid ring pump can be obtained according to (1), (4), and (6).

The capacity of gas returning to the suction zone of liquid ring pump is calculated by

$$
q_{0}=\mu \int_{r_{1}}^{r_{\varphi=2 \pi}} \omega r b d r=\frac{1}{2} \mu \omega b\left(r_{\varphi=2 \pi}^{2}-r_{1}^{2}\right),
$$

where $r_{\varphi=2 \pi}$ is the distance from the liquid ring surface at the circumferential angle $\varphi=2 \pi$ to the center of the impeller. The gas capacity $q_{0}$ changes to $q_{e}$ after a polytropic expansion process and then enters the next operating cycle:

$$
q_{e}=q_{0}\left(\frac{p_{d}}{p_{s}}\right)^{1 / m}
$$

Therefore, the actual suction capacity of liquid ring pump is expressed as

$$
\begin{aligned}
& q_{s} \\
& = \begin{cases}0 & p_{s} \leq p_{v} \\
\frac{1}{2} \mu \omega b r_{2}^{2}\left[(1-\alpha)^{2}-v^{2}\right]-q_{0}\left(\frac{p_{d}}{p_{s}}\right)^{1 / m} & p_{s}>p_{v} .\end{cases}
\end{aligned}
$$

Then the actual discharge capacity $q_{d}$ can be calculated according to the isothermal compression process:

$$
q_{d}=\frac{q_{s} p_{s}}{p_{d}}
$$

2.2. Shaft Power Model of Liquid Ring Pump. The effective power of the liquid ring pump is generally calculated according to the isothermal compression power. However, accurate prediction of shaft power $N$ is essential for estimating global efficiency and studying how to reduce power consumption in a liquid ring pump. The shaft power is mainly composed of two parts: the total power consumption $N_{g}$ of the gas and the friction loss $N_{l}$ of the operating liquid. The total power consumption of the gas is the adiabatic compression work:

$$
N_{g}=\frac{\kappa}{\kappa-1} p_{s} q_{\text {th }}\left[\left(\frac{p_{d}}{p_{s}}\right)^{(\kappa-1) / \kappa}-1\right] .
$$

The empirical formula of the liquid friction loss $N_{l}$ in liquid ring pump for the turbulent flow was given by Prager [19]:

$$
\begin{aligned}
& N_{s}=0.708 \frac{\rho}{2} \omega^{3} r_{2}^{5} \operatorname{Re}^{-0.1732}, \\
& \operatorname{Re}=\frac{\omega r_{2}^{2}}{v} .
\end{aligned}
$$

It is found that axial width $b$ of the impeller is usually big in liquid ring pumps but not yet considered in Prager's equation (12). By referring to the formula of disk friction power in centrifugal pump [20], the equation (12) of liquid friction loss $N_{l}$ can be corrected as

$$
N_{l}=0.708 \frac{\rho}{2} \omega^{3} r_{2}^{5} \operatorname{Re}^{-0.1732}\left(1+f \frac{b}{r_{2}}\right)
$$

Therefore, the shaft power of liquid ring pump is written as

$$
\begin{aligned}
N= & N_{g}+N_{l} \\
= & \frac{\kappa}{\kappa-1} p_{s} q_{\text {th }}\left[\left(\frac{p_{d}}{p_{s}}\right)^{(\kappa-1) / \kappa}-1\right] \\
& +0.708 \frac{\rho}{2} \omega^{3} r_{2}^{5} \operatorname{Re}^{-0.1732}\left(1+f \frac{b}{r_{2}}\right) .
\end{aligned}
$$

The global efficiency $\eta$ is finally estimated by the following expression [13]:

$$
\eta=\frac{p_{s} q_{s} \ln \left(p_{d} / p_{s}\right)}{N}
$$

\section{Performance Tests of Liquid Ring Pumps}

To validate the feasibility of the proposed theoretical models on performance of liquid ring pumps, the performance tests of the liquid ring pumps were performed. Three types of single-stage double-acting liquid ring vacuum pumps (2BE1103, 2BE1253, and 2BE1353) were selected for performance tests. The design and operating parameters of the liquid ring vacuum pumps are listed in Table 2. Water and air were the operating liquid and gas in the tests, and room temperature was maintained at $28^{\circ} \mathrm{C}$. The tests were performed under different rotational speed of the pumps by frequency control. A multiparameter data acquisition and processing system were used in the performance tests and the detailed measurement method was introduced in [21]. The experimental facility and the layout of measurement device are shown in Figure 4.

\section{Comparisons of Performance between Test and Theoretical Models}

4.1. Suction Capacity of Liquid Ring Pump. Figure 5 shows the comparisons between the tested suction capacity $q_{s}$ values and theoretical ones from (3), Prager's equation, Powle's equation, and (9) ( $m=1.4$ for adiabatic expansion) under different rotational speeds, in which $q_{s \max }$ in Prager's equation and $q_{d \text { max }}$ in Powle's equation are provided by (9). From the performance curves, it can be seen that the results of (9) under the adiabatic expansion process are close to the test results. The predicted suction capacities of the liquid ring vacuum pumps are within $15 \%$ relative error for all rotational speeds. The average relative errors of predicted values by different models are within $10 \%$ for three types of pumps at various rotational speeds as shown in Table 3 . This 


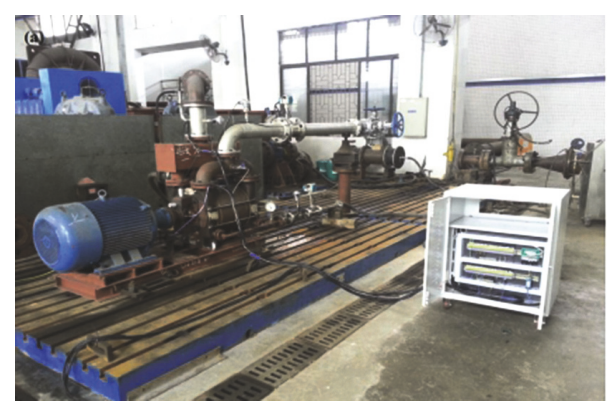

(a) Experimental apparatus

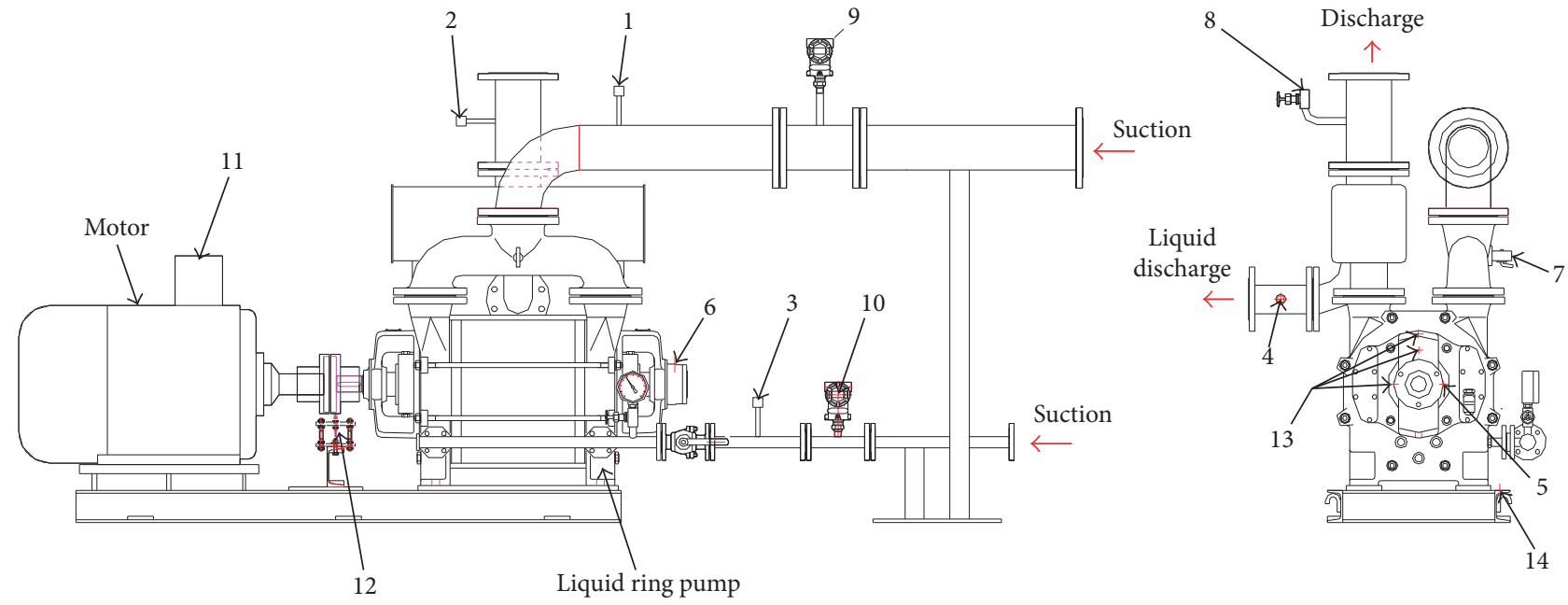

(b) Layout of monitoring points

FIGURE 4: Experimental facility. 1-suction temperature; 2-discharge temperature; 3-liquid suction temperature; 4-liquid discharge temperature; 5-drive bearing temperature; 6-nondriven bearing temperature; 7-suction pressure; 8-discharge pressure; 9-air capacity; 10-liquid capacity; 11-power; 12-rotational speed; 13-X/Y/Z-direction vibration; 14-substructure vibration.

TABLE 2: Parameters of liquid ring vacuum pump.

\begin{tabular}{|c|c|c|c|c|c|}
\hline Category & Parameter & Unit & 2BE1103 & 2BE1253 & 2BE1353 \\
\hline Casing & Radius $R$ & $\mathrm{~m}$ & 0.1365 & 0.3145 & 0.407 \\
\hline \multirow{8}{*}{ Impeller } & Rotational speed $n$ & $\mathrm{r} / \mathrm{min}$ & $1170,1300,1450$ & $590,740,920$ & $372,490,590$ \\
\hline & Axial width $b$ & $\mathrm{~m}$ & 0.215 & 0.5 & 0.708 \\
\hline & Angle of blade $\beta$ & Degree & 40 & 42 & 45 \\
\hline & Impeller radius $r_{2}$ & $\mathrm{~m}$ & 0.105 & 0.25 & 0.36 \\
\hline & Hub radius $r_{1}$ & $\mathrm{~m}$ & 0.0535 & 0.125 & 0.177 \\
\hline & Eccentricity $e$ & $\mathrm{~m}$ & 0.0136 & 0.0316 & 0.04 \\
\hline & Blade thickness $\delta$ & $\mathrm{m}$ & 0.008 & 0.01 & 0.012 \\
\hline & Blade number $Z$ & & 12 & 15 & 18 \\
\hline
\end{tabular}

indicates that the expansion process of the residue gas is near the adiabatic one due to a shorter expansion time and path. In addition, Prager's and Powle's equations can also provide reasonable predictions of $q_{s}$, if $q_{s \text { max }}$ and $q_{d \text { max }}$ are calculated by (9).

4.2. Shaft Power of Liquid Ring Pump. Figure 6 shows the comparisons between the tested shaft power $N$ values and theoretical ones by (15) in liquid ring pump under different rotational speeds. From Figure 6, it can be seen that the trends of the shaft power curves calculated by (15) agree well with the ones of the test results. The shaft power predictions of the liquid ring vacuum pumps are within $13 \%$ relative error for all rotational speeds. The average relative errors of predicted values by the proposed model are within 10\% for three types of pumps at various rotational speeds as shown in Table 3. This means the effect of axial width $b$ of the impeller should be taken into account for liquid friction loss in liquid ring 

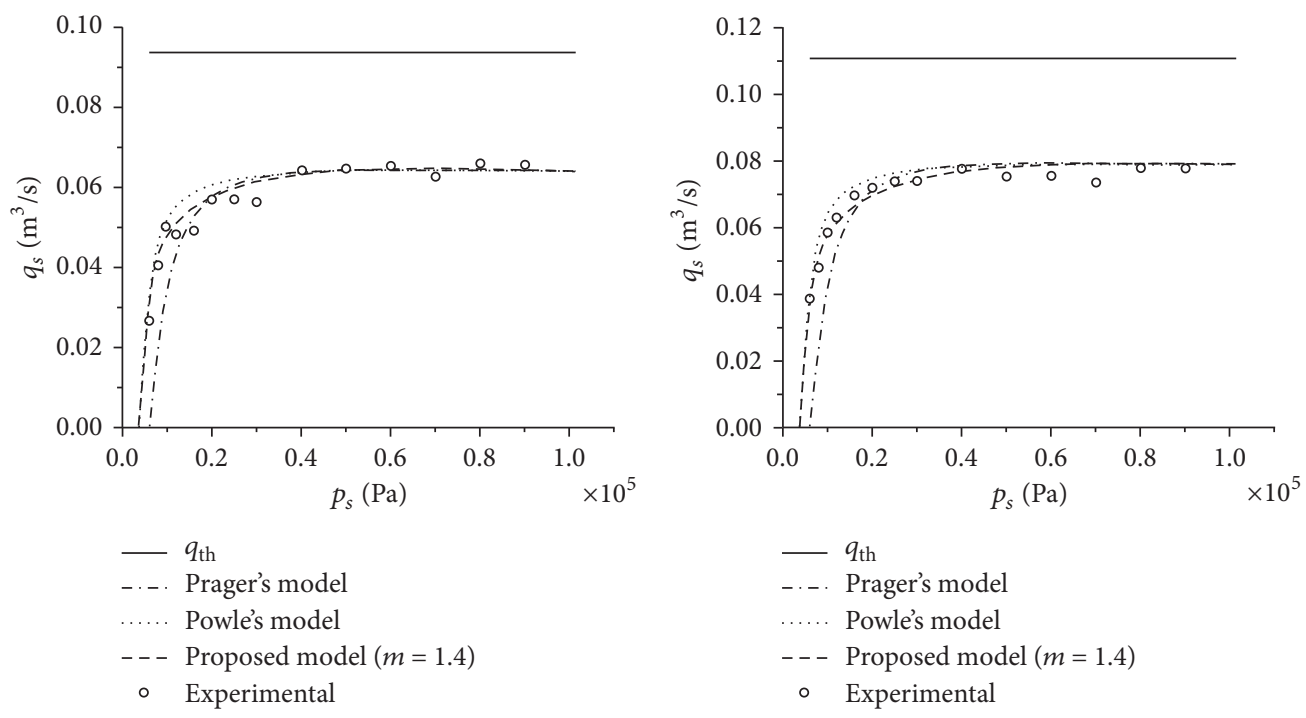

(b) $n=1300 \mathrm{r} / \mathrm{min}$, type: $2 \mathrm{BE} 1103$

(a) $n=1170 \mathrm{r} / \mathrm{min}$, type: $2 \mathrm{BE} 1103$
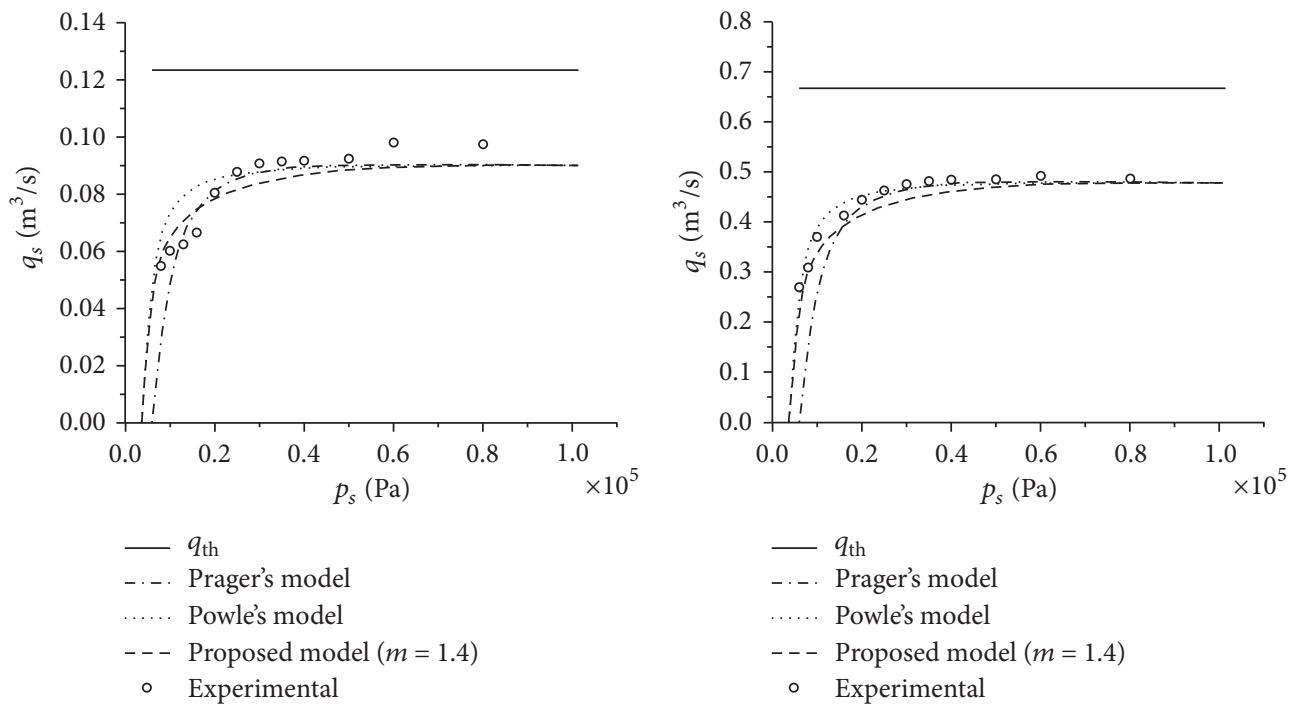

(d) $n=590 \mathrm{r} / \mathrm{min}$, type: $2 \mathrm{BE} 1253$
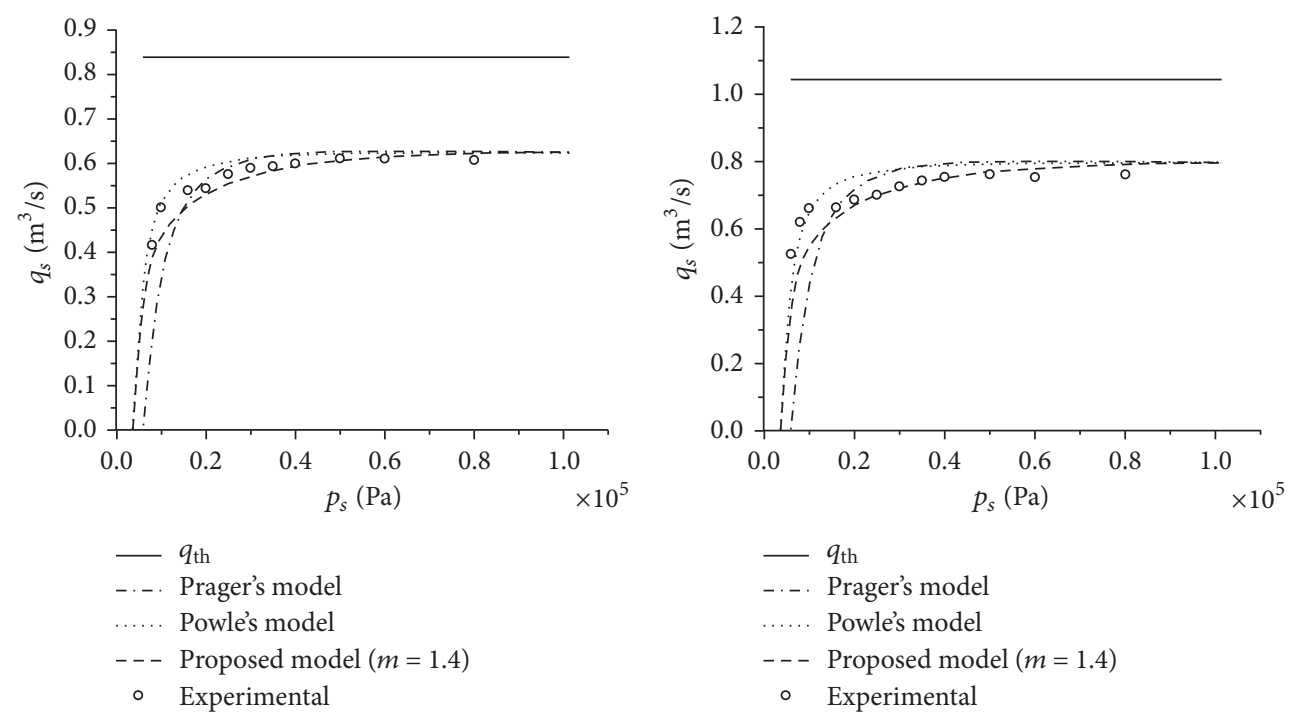

(f) $n=920 \mathrm{r} / \mathrm{min}$, type: $2 \mathrm{BE} 1253$

Figure 5: Continued. 


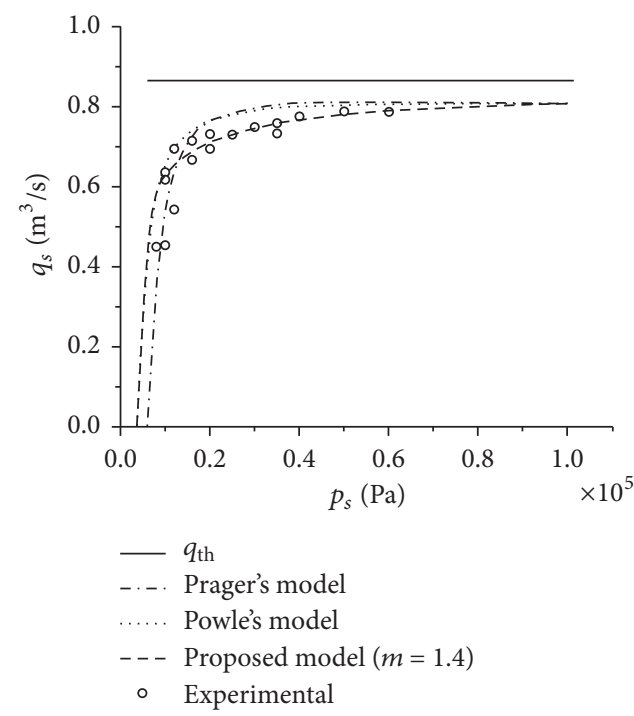

(g) $n=372 \mathrm{r} / \mathrm{min}$, type: $2 \mathrm{BE} 1353$

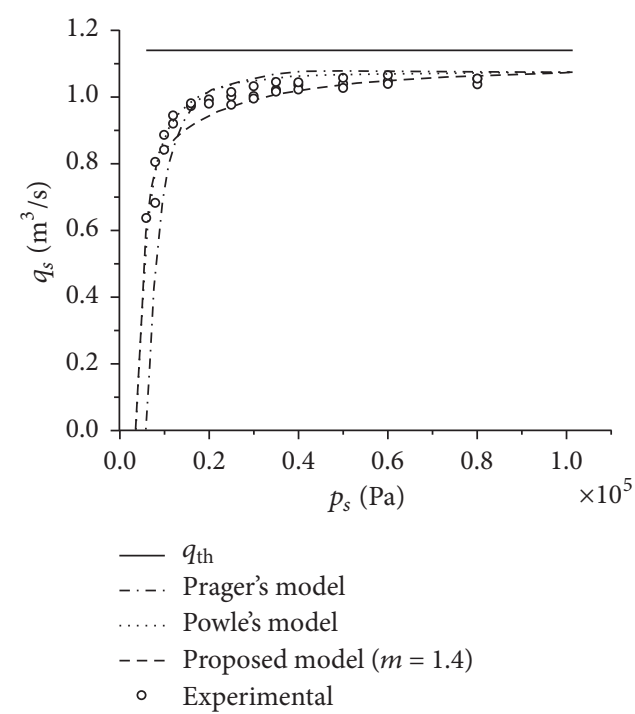

(h) $n=490 \mathrm{r} / \mathrm{min}$, type: $2 \mathrm{BE} 1353$

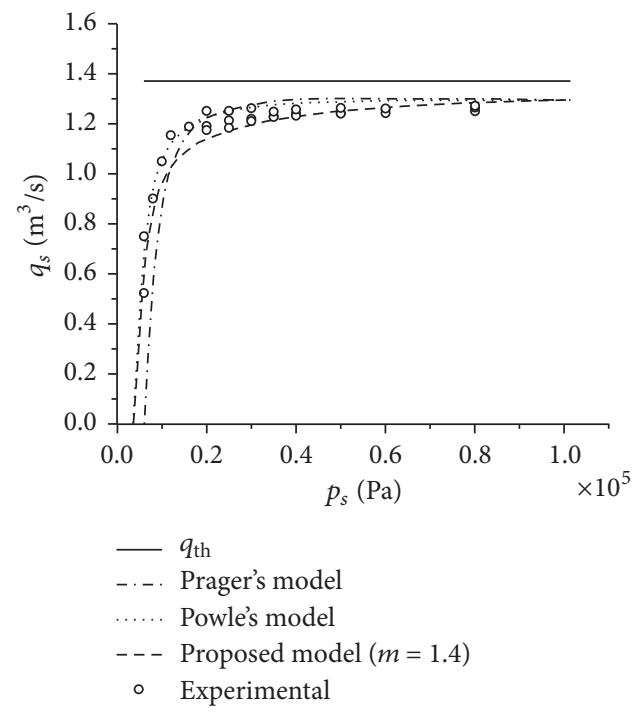

(i) $n=590 \mathrm{r} / \mathrm{min}$, type: $2 \mathrm{BE} 1353$

Figure 5: Comparisons of $q_{s}-p_{s}$ curves between the test and theoretical models.

TABLE 3: Average relative errors of predicted models.

\begin{tabular}{|c|c|c|c|c|c|c|c|c|c|c|}
\hline Type of pump & Average relative errors (\%) & \multicolumn{3}{|c|}{ Prager's model } & \multicolumn{3}{|c|}{ Powle's model } & \multicolumn{3}{|c|}{ Proposed model } \\
\hline \multirow{3}{*}{ 2BE1103 } & $n(\mathrm{r} / \mathrm{min})$ & 1170 & 1300 & 1450 & 1170 & 1300 & 1450 & 1170 & 1300 & 1450 \\
\hline & $\Delta q_{s}$ & 5.23 & 4.25 & 5.41 & 4.68 & 5.36 & 10.06 & 1.77 & 1.83 & 5.32 \\
\hline & $\Delta N$ & - & - & - & - & - & - & 6.43 & 4.87 & 6.69 \\
\hline \multirow{3}{*}{ 2BE1253 } & $n(\mathrm{r} / \mathrm{min})$ & 590 & 740 & 920 & 590 & 740 & 920 & 590 & 740 & 920 \\
\hline & $\Delta q_{s}$ & 4.17 & 7.13 & 9.38 & 4.27 & 5.02 & 5.80 & 3.34 & 2.99 & 4.94 \\
\hline & $\Delta N$ & - & - & - & - & - & - & 6.40 & 10.53 & 7.62 \\
\hline \multirow{3}{*}{ 2BE1353 } & $n(\mathrm{r} / \mathrm{min})$ & 372 & 490 & 590 & 372 & 490 & 590 & 372 & 490 & 590 \\
\hline & $\Delta q_{s}$ & 8.85 & 7.38 & 7.07 & 12.95 & 4.01 & 4.52 & 8.66 & 1.88 & 1.40 \\
\hline & $\Delta N$ & - & - & - & - & - & - & 5.02 & 4.66 & 4.46 \\
\hline
\end{tabular}




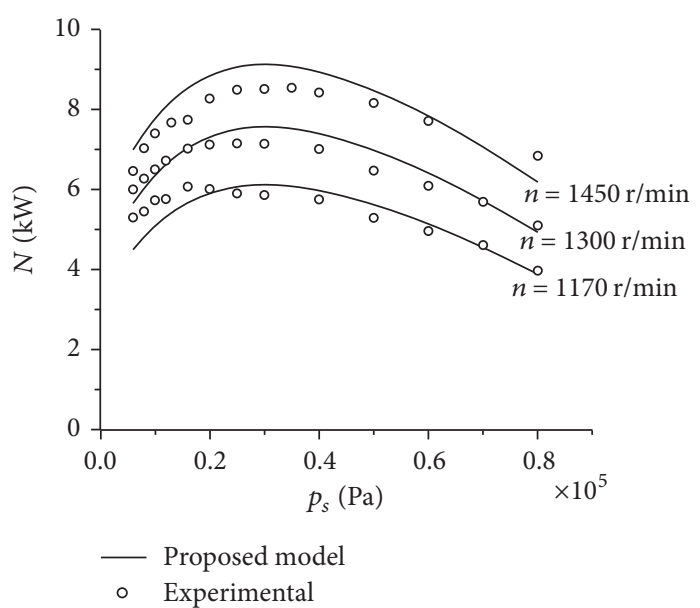

(a) Type: $2 \mathrm{BE} 1103$

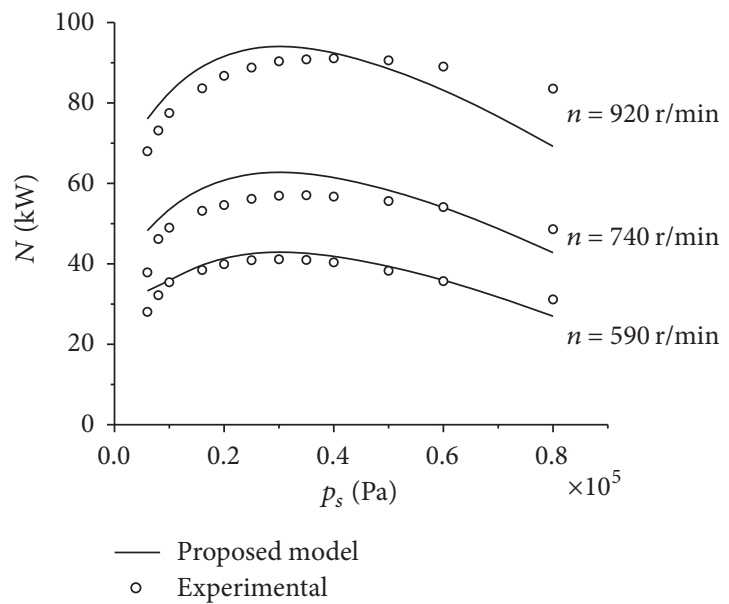

(b) Type: 2BE1253

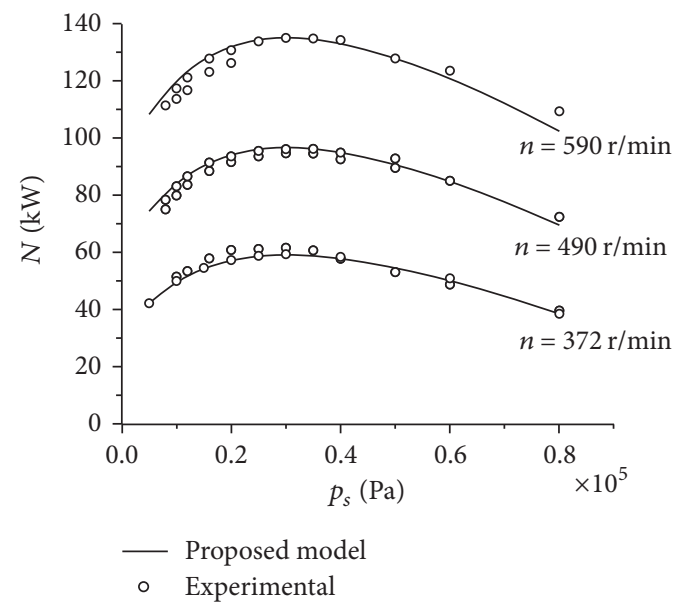

(c) Type: $2 \mathrm{BE} 1353$

Figure 6: Comparisons of $N-p_{s}$ curves between the test and theoretical model.

pump. More sophisticated models for shaft power of liquid ring pump are necessary to consider for higher predictive accuracy in further work.

\section{Conclusions}

Based on the actual operating cycle of "suction-compressiondischarge-expansion," a universal theoretical model for performance of liquid ring pump was established and verified by performance test in this study. Some conclusions are summarized as follows:

(1) Considering expansion process of the residual gas in liquid ring pumps is an effective approach to solve the problem that the theoretical models deviate from the actual performance in operating cycle. The expansion process is likely near the adiabatic one due to a shorter expansion time and path.

(2) With the major geometric parameters and operating conditions of a liquid ring pump, the performance parameters such as the actual capacity for suction and discharge, shaft power, and global efficiency can be conveniently predicted using the proposed theoretical model, without the limitation of empiric range, performance data, or the detailed 3D geometry of pumps.

(3) The effect of axial width of the impeller should be taken into account for liquid friction loss in liquid ring pump model.

\section{Nomenclature}

A: Coefficient

$B$ : Coefficient

$N$ : Shaft power, $\mathrm{W}$

$R$ : Inner radius of casing, $\mathrm{m}$

Re: Reynolds number

$a$ : Immersion depth of the blades, $\mathrm{m}$

$b$ : Impeller width, $\mathrm{m}$

$e:$ Impeller eccentricity, $e<R-r_{2}, \mathrm{~m}$

$f$ : Coefficient in friction power considering effect of impeller width, $f=0.15$

$m$ : Gas expansion index, $1<m<\kappa$ 
$n$ : Impeller rotational speed, $\mathrm{r} / \mathrm{min}$

$p$ : Pressure, $\mathrm{Pa}$

$q$ : Volumetric capacity, $\mathrm{m}^{3} / \mathrm{s}$

$r$ : Radius, $m$

$u$ : Circumferential speed of impeller, $\mathrm{m} / \mathrm{s}$

$Z$ : Blade number.

\section{Greek Letters}

$\alpha$ : Relative immersion depth of the blades

$\beta$ : Angle of blade, degree

$\delta$ : Blade thickness, $\mathrm{m}$

$\varepsilon$ : Coefficient

$\eta$ : Global efficiency of liquid ring pump

$\varphi$ : Circumferential angle, degree

$\kappa:$ Adiabatic index; for air, $\kappa=1.4$

$\lambda$ : Flow coefficient

$\mu$ : Coefficient considering the effect of blade thickness, $\mu=0.68 \sim 0.85$

$v$ : Kinematic viscosity, $\mathrm{m}^{2} / \mathrm{s}$

$\rho$ : Length, $\mathrm{m}$; density, $\mathrm{kg} / \mathrm{m}^{3}$

$\sigma$ : Compression ratio

$\omega$ : Angular speed of impeller, $\omega=2 \pi n / 60$, $\mathrm{rad} / \mathrm{s}$

$v$ : Ratio of hub radius to impeller radius, $v=r_{1} / r_{2}$.

\section{Subscripts}

a: Atmospheric

d: Discharge

e: Expansion

g: Gas

$l$ : Operating liquid

$s$ : Suction

$v$ : Saturated vapor

th: Theoretical

0 : Residual gas

1: Impeller hub

2: Impeller.

\section{Conflicts of Interest}

The authors declare that they have no conflicts of interest.

\section{References}

[1] W. Burgmann and K. Göhler, "Modern vacuum pumps for the vacuum degassing of steel in small and large vacuum-degassing units," Metallurgist, vol. 57, no. 5-6, pp. 516-525, 2013.

[2] A. V. Kravtsov and O. A. Troshkin, "Enhancement of operational characteristics of liquid-piston compressors based on new designs," Chemical and Petroleum Engineering, vol. 46, no. 11-12, pp. 675-676, 2011.

[3] H. M. Yu, "Analysis on selection of water ring vacuum pumps in the chemical industry," Applied Mechanics and Materials, vol. 327, pp. 1435-1439, 2013.

[4] Y. M. Vertepov, V. N. Matsenko, and V. M. Antonov, "Advances in water-ring vacuum pumps and compressors," Chemical and Petroleum Engineering, vol. 33, no. 5, pp. 522-523, 1997.
[5] C. Schreiber and M. Kopf, "New application horizons for liquid ring vacuum pumps-extended capabilities in combinations with side channel blowers," Vakuum in Forschung und Praxis, vol. 26, no. 6, pp. 26-31, 2014.

[6] N. D. Karlsen-Davies and G. A. Aggidis, "Regenerative liquid ring pumps review and advances on design and performance," Applied Energy, vol. 164, pp. 815-825, 2016.

[7] C. Pfleiderer, Centrifugal Pump for Liquids and Gases, Berlin, Germany, 1961.

[8] H. Schulz, The Pumps, Berlin, Germany, 1977.

[9] U. Segebrecht, Liquid Ring Vacuum Pumps and Liquid Ring Compressors: Technical Details and Fields of Application, Verlag Moderne Industrie, Landsberg am Lech, Germany, 1994.

[10] R. Prager, "Operational Conditions and Application Field of Liquid-Ring Machines," in Proceedings of the Third Conference on Fluid Mechanics and Fluid Machinery, 1969.

[11] U. S. Powle and S. Kar, "Investigations on pumping speed and compression work of liquid ring vacuum pumps," Vacuum, vol. 33, no. 5, pp. 255-263, 1983.

[12] W. H. Faragallah, 1988, Liquid Ring Vacuum Pumps and Compressors, Gulf.

[13] H. Bannwarth, Liquid Ring Vacuum Pumps, Compressors and Systems: Conventional and Hermetic Design, John Wiley \& Sons, Compressors and Systems: Conventional and Hermetic Design, 2006.

[14] I. S. Bodik and A. B. Tishchenko, "Effect of impeller circumferential velocity on the specific power demand of water-ring vacuum pumps," Chemical and Petroleum Engineering, vol. 24, no. 6, pp. 289-290, 1988.

[15] S. Huang, R. Zhi-Yong, Q. J. Deng, W. U. Tai-Zhong, and Z. H. Tan, "Numerical analysis of gas-liquid two-phase flow in liquidring vacuum pump," Vacuum, vol. 46, no. 2, pp. 49-52, 2009.

[16] K. Kakuda, Y. Ushiyama, S. Obara et al., "Flow simulations in a liquid ring pump using a particle method," Computer Modeling in Engineering and Sciences, vol. 66, no. 3, pp. 215-226, 2010.

[17] M. Radle and B. Shome, "Cavitation prediction in liquid ring pump for aircraft fuel systems by CFD approach," in Proceedings of the SAE 2013 Aerotech Congress, 2013.

[18] H. Ding, Y. Jiang, H. Wu, and J. Wang, "Two phase flow simulation of water ring vacuum pump using VOF model," in Proceedings of the ASME/JSME/KSME 2015 Joint Fluids Engineering Conference, Seoul, Republic of Korea, July 2015.

[19] R. Prager, Investigation into Liquid Ring Vacuum Pumps and Compressors for the Determination of Performance Losses, Dissertation, Dresden, Germany, 1968.

[20] A. Nemdili and D. H. Hellmann, "Investigations on fluid friction of rotational disks with and without modified outlet sections in real centrifugal pump casings," Forschung im Ingenieurwesen, vol. 71, no. 1, pp. 59-67, 2007.

[21] G. Q. Qiu, S. Huang, L. L. Zhu, Y. Chen, and J. He, "Performance monitoring analysis of liquid ring vacuum pumps," Applied Mechanics and Materials, vol. 853, pp. 463-467, 2017. 


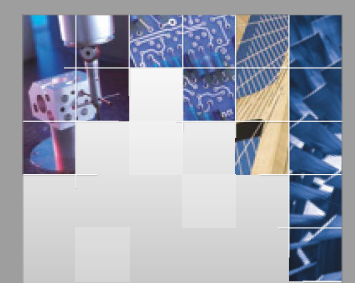

\section{Enfincering}
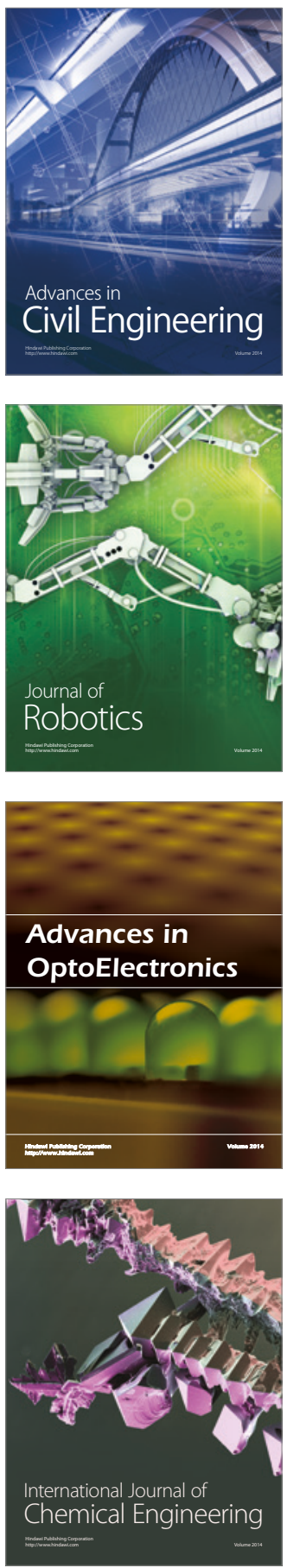

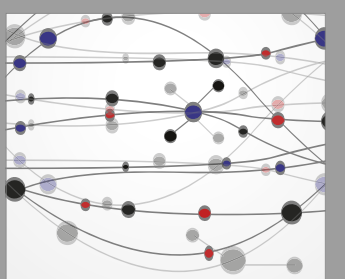

The Scientific World Journal

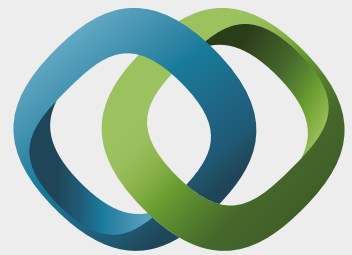

\section{Hindawi}

Submit your manuscripts at

https://www.hindawi.com
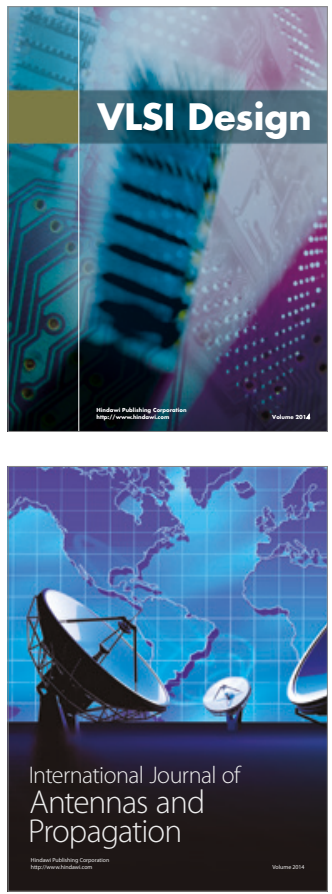

\section{Rotating}

Machinery
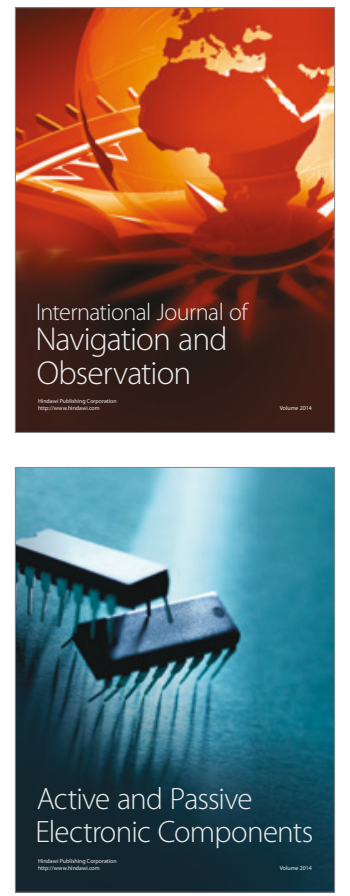
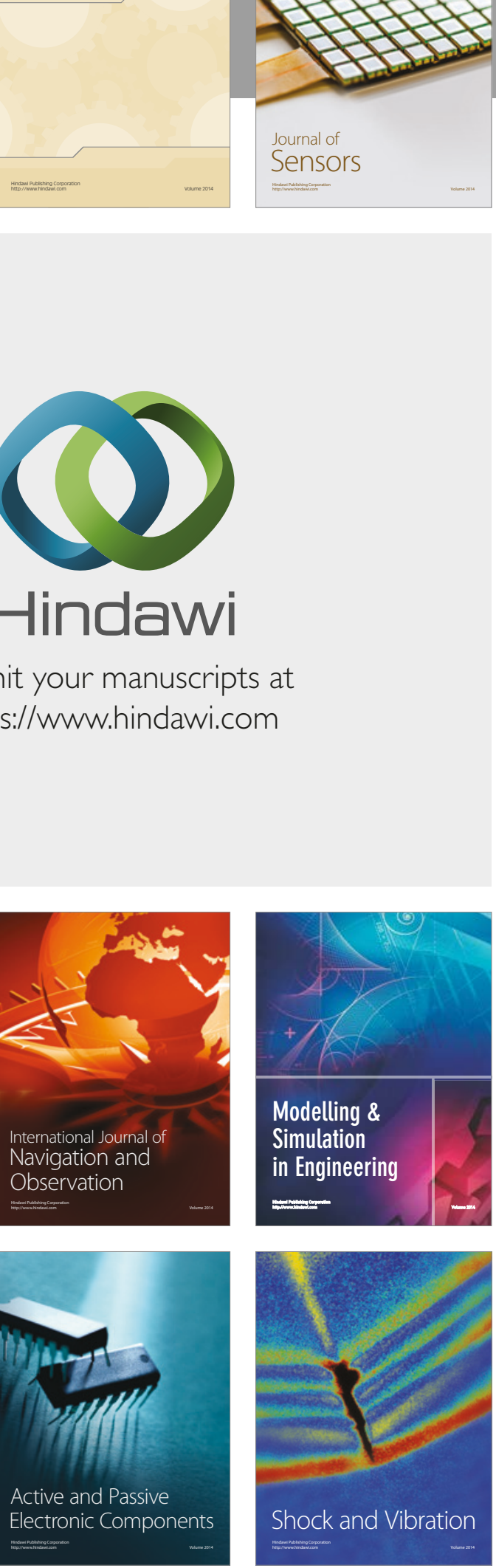
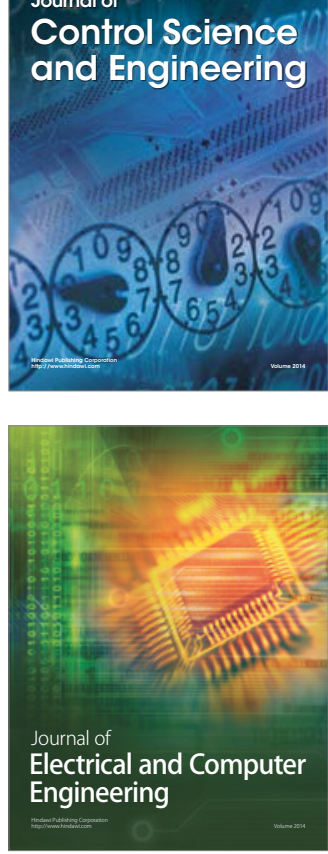

Distributed

Journal of

Control Science

and Engineering
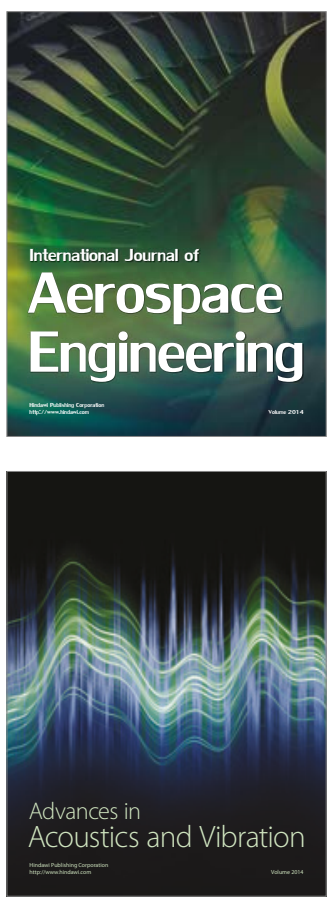

Sensor Networks 